\title{
Engineered Bamboo's Further Application: An Empirical Study in China
}

\author{
WQ Xing, JL Hao, I Galobardes, SB Wei, ZT Chen, KS Sikora \\ Xi'an Jiaotong-Liverpool University, Suzhou, P. R. China
}

\begin{abstract}
The trend of sustainable development has been followed more globally nowadays. There is an urgent need for ecological friendly construction materials in China since the use of concrete produces pollution and leads to inefficient use of energy. Bamboo can effectively address the sustainability trends due to: lightweight construction, little adverse impact on the environment, and anti-seismic properties. However, bamboo products utilization has been very limited. Therefore, the purpose of this study was to investigate the feasibility to further utilize bamboo products in the construction industry in China. A review of engineered bamboo products utilization in China, and oversees was conducted. Based on this, a survey focusing on the current situation and suitability of bamboo products was carried out to study their feasibility, and preliminary testing on bonding shear strength for different configurations are presented. The results are promising, in particular the relatively low clamping pressure of 0.6 MPa seems to be sufficient for bonding, and it is clear that engineered bamboo products have a great potential in China. However, further more comprehensive studies on the performance of the laminated bamboo are needed.
\end{abstract}

\section{Introduction}

Bamboo is a traditional material used for construction in ancient China. In general bamboo's mechanical and durability properties are comparable or excessing values of the materials used traditionally in construction, like concrete or timber [1]. China is the main origin of bamboo in the world, considering the species, distribution area and quantity [2]. Bamboo is distributed in a wide range in China, see Figure 1; in four provinces: Fujian, Zhejiang, Jiangxi and Hunan, it occupies about $60.8 \%$ of China bamboo forest area [3]. In the world, there are bamboos of total 150 genera, 1,253 species and 2,200 million hectares. Bamboos in China have 43 genera, 707 species and the distribution area of bamboo in China covers about 700 million hectares [2]. The major bamboo species in China is Moso bamboo.

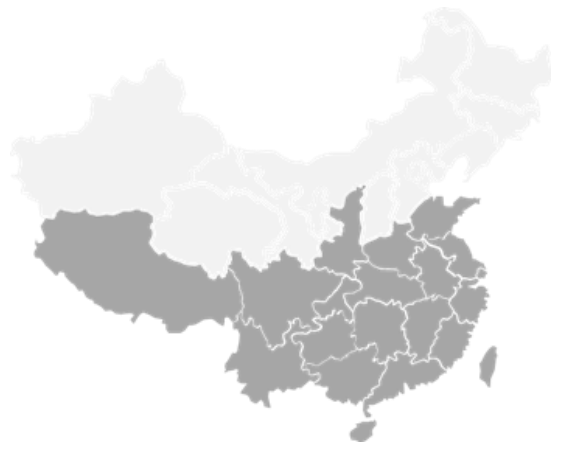

Figure 1. China's bamboo growing province map [3]

\section{Current utilization of bamboo}

\subsection{China}

Bamboo is mainly applied to construction industry without further processing. After economic reform policy (the program of economic reforms termed 'Socialism with Chinese characteristics' in P. R. China that was started in December 1978) the development process of bamboo-related industry made a considerable progress. New bamboo-based products such as bamboo ply and laminated bamboo strips appear to deal with the problem of poor forestry resources to some extent [4]. Nevertheless, these bamboo products are rarely used in construction filed; they are often used for furniture, floors and walls. Based on The Third National Industrial Census [5], China has 1,120 companies involved in bamboo products and only $9.2 \%$ are related to construction industry.

\subsection{World}

Potential for bamboo construction is mainly in Latin America and Southeast Asia because both regions abound in bamboo [6]. Columbia has the advanced technology of raw bamboo building construction and more than 700 low-cost bamboo residences has been built in Costa Rica. Southeast Asian countries such as Vietnam, India, Indonesia and Thailand have been researching the usage of raw bamboo in construction.

Although bamboo in Europe is not abundant or widely distributed, authorities of few European countries have made some achievements about technology of bamboo construction to follow the trend of sustainable 
development [6]. For instance, in Germany there have been established the complete standard to guide the construction of bamboo-made building. In general, glued laminated bamboo and bamboo based panel are two types that can be used in modern bamboo structures [7]. Their strength and stiffness promote the bamboo to be the material for multi-storey and large-span construction.

\section{Physical and mechanical properties of bamboo}

Bamboo is one of the fastest-growing plant on earth, whose growth rate of bamboo can be up to $91 \mathrm{~cm}$ per day [8]. Its rate of productivity and cycle of annual harvest outstrips other naturally growing resource; three years is enough for bamboo to be mature for construction usage. Besides, bamboo as a plant can absorb a large amount of $\mathrm{CO}_{2}$ [9]. Generally, bamboo could be divided into two kinds, clumping and running [3]. The clumping types are typically of tropical or subtropical origin, with high growing rate. On the other hand, running bamboo can withstand occasional low winter temperatures, but it needs several years to be mature. In theory, the mechanical properties of cut bamboo elements depend on the botanical species, the age at which the bamboo has been cut, the moisture content, the position along the culm, and the position of the nodes. Bamboo is functionally graded composite and orthotropic material, its load bearing capacity is related to the distribution of the fibers, and having high strength along and low strength transversal to its fibers respectively. Bamboo has a low density but high stiffness, its shrinkage is smaller than timber, and the elasticity and toughness are high enough. Moreover, due to the unique shape of bamboo, bending resistances of bamboo are same for each internode [10]. As for nodes, they are weaker in compression and bending than internodes [9].

With regard to the disadvantages of the bamboo, raw cut bamboo is a hollow tube, sometimes with thin walls, and therefore it is hard to join pieces of bamboo. Secondly, the outer skin of a culm cannot be glued without treatment, because of its high silica contents. Furthermore, bamboo also can have some defects due to an action of insects. Low natural durability of bamboo indicates that it needs preservative treatment, which is difficult in many cases [11].

\section{Challenges and potential with new developments}

\subsection{Engineered bamboo products}

Engineered bamboo possesses the advantages of raw bamboo while overcomes some of its disadvantages. In recent years, several typical engineered bamboo products such as bamboo ply, strand woven bamboo and glued laminated bamboo have been researched and produced, and they can be composited with other structural materials such as timber and reinforced concrete. These products are made from veneers, strands and sliced piece of bamboo, which are combined into a specific structure and then bonded together with adhesives by high-pressure and/or high-temperature. This process improves significantly parameters when comparing to natural product allowing utilization of species of lower properties that were not considered before for high performance usage.

\subsection{Preliminary testing: Materials \& Methodology}

To assess the shear strength of adhesive bonds that is a critical property for bamboo utilization in big scale construction engineered bamboo panels an experimental program has been initiated at Xi'an Jiaotong-Liverpool University. Commercially available, one-ply vertically laminated bamboo panel made from Chinese Moso bamboo with age of 3 to 5 years is used for this testing to prepare the specimens. The panel cut to specimens with bonding area of $30 \mathrm{~mm} \times 50 \mathrm{~mm}$ glued using a hybrid polymer adhesive (HPA). Specimens are manufactured following the grain directions of bamboo that parallel and perpendicular to the grain, and cross laminated directions that cross laminated vertically and horizontally, to the bamboo material. Different clamping pressures, 0.6 MPa, $0.8 \mathrm{MPa}$ and $1.0 \mathrm{MPa}$ are applied in order to find out the optimal production pressures. Testing method follows the methodology developed for laminated timber by Sikora et al. [12], with the uniform rate of $3 \mathrm{~mm} / \mathrm{min}$. Block shear tests of specimens in four different configurations, endgrain, perpendicular to grain, cross laminated vertically and cross laminated horizontally were carried out.

\subsection{Results and discussion}

Table 1 presents results for 4 different loading configurations and for 3 different clamping pressures, and each result represents average value for the tests of 10 specimens.

As the percentages of bamboo grain failure were $0.0 \%$ for all specimens, it can be claimed that the failure is attributed to the failure of adhesive. In addition, there is no direct tendency for all the results since they perform similarly under different loading configurations. Therefore, it can be generally concluded that different clamping pressures have not significant effects on shear strength of HPA glued bamboo specimens. Moreover, almost all the bonding shear strengths of these specimens have exceeded $1.5 \mathrm{MPa}$, which is the standard strength data provided by manufacture industry of HPA adhesive. The experiment results give an evidence that although HPA is used for furniture and sealing normally, it provides the proper interface bond and penetration to the natural bamboo products as well. This confirms that bamboo panels have reasonable high strengths in both directions, higher than hybrid polymer adhesive. Furthermore, the lowest clamping pressure used $(0.6 \mathrm{MPa})$ is sufficient for bonding the bamboo elements, and the highest pressure (1 MPa) seems to be more suitable for cross laminated bamboo production, presenting the highest strength results. 
Table 1. The bonding shear strength of glued laminated bamboo (coefficients of variation in brackets)

\begin{tabular}{c|c|c|c}
\hline CHARACTERISTIC & \multicolumn{3}{|c}{ BONDING SHEAR STRENGTH (MPa) } \\
CLAMPING PRESSURE & $0.6 \mathrm{MPa}$ & $0.8 \mathrm{MPa}$ & $1.0 \mathrm{MPa}$ \\
End-grain & $1.80(58.9 \%)$ & $1.61(17.4 \%)$ & $1.73(23.7 \%)$ \\
Perpendicular to grain & $1.81(20.4 \%)$ & $1.67(20.4 \%)$ & $1.74(28.2 \%)$ \\
Cross laminated vertically & $1.57(14.0 \%)$ & $1.38(24.0 \%)$ & $2.00(27.0 \%)$ \\
Cross laminated horizontally & $1.43(27.3 \%)$ & $1.58(24.7 \%)$ & $2.1242 .0 \%)$ \\
\hline
\end{tabular}

\subsection{Challenges from Chinese perspective}

Bamboo utilization in construction in China facing several possible challenges. First of all, there is no national standard for bamboo construction in China. Until now, the application of bamboo in constructions still follows the Code for Design of Timber Structures [7], but the characteristics of bamboo are different from timber. Lack of standard, as a result, limits the development of bamboo products utilization in construction. Secondly, the high cost of bamboo construction is also an important issue affecting its improvement. The production scale of bamboo frame is still at an initial stage and the production efficiency is low; machinery cost is high as well. With regard to consumers, they normally consider initial cost of material purchase the most. Although the cost of bamboo frame construction is lower than other materials considering maintenances cost, most consumers just focus on the short-term benefits, which also obstructs the use of bamboo [13]. Moreover, technology limits the development of bamboo construction. In China, timber construction has been neglected for the past few decades, accordingly, the knowledge on bamboo technology is also outdated. There is only one university, Hunan University that delivers bamboo construction courses at present in China, which limits bamboo technology development in the near future [7].

\section{5 Potential for China}

Firstly, environment in China has been polluted severely, partially due to the use of concrete in construction industry, which productions requires high energy consumption. Bamboo as a material providing renewable, durable, energy-efficient and cost-efficient solutions, and it can act as substitute of concrete to some extent to mitigate the problem of vast energy consumption and severe environmental impact. There is much space for bamboo to develop since $99 \%$ buildings in China are constructed with concrete [14]. Additionally, since China has the richest bamboo resources in the world, bamboo is abundant enough for Chinese construction industry to satisfy its huge requirements in terms of quantities. Moreover, China and other countries have researched and developed new technologies related to engineered bamboo products [7], therefore engineered bamboo products are more likely to be competitive in cost, strength and sustainability, than other traditional materials. Furthermore, a series of standards related to bamboo buildings are under development and review in China.
The potential of introduction regulations for bamboo building construction is being studied so that to promote the range of bamboo building usage [6]. With these specific construction regulations, bamboo is more suitable for the particular areas of China: urban areas where lowrise house is allowed only and suburb areas with lower land price and beautiful scenery. What is more, there is an increasing demand for various types of structure houses in metropolitans such as Shanghai, Beijing and Shenzhen. Another possible potential for bamboo is related to active seismic zones in China. Light weight and ductility of bamboo allows to absorb seismic energy without collapse.

\section{Survey of the industry}

\subsection{Introduction and methodology}

To investigate the current situation and suitability of bamboo for the manufacture of laminated panel a survey of the construction industry was made. A questionnaire was designed (in Chinese and English language) consisting of over 20 questions related to current usage of different materials for construction projects, and predictions for future, based on the current trends. Feedback was obtained from carefully selected 9 industry members representing consulting and architecture companies who are the main decision-makers on the type of the construction material used for the projects.

\subsection{Results and discussion}

From feedback, participants were mainly from private companies (7 participants) with less than 300 employees and the other two participants represented public company and public institution. Their field of business covers consulting (5 of 9), architecture (3 of 9) and research (1 of 9). Although area served are national $(77.8 \%)$ or worldwide $(22.2 \%)$, their companies are concentrated on Shanghai and Suzhou.

The three most important characteristics that participants take into consideration when selecting materials are strength $(66.7 \%)$, durability $(55.6 \%)$ and fire resistance $(55.6 \%)$, see Figure 2 . However, material cost (44.4\%) and construction cost $(44.4 \%)$ are also important for these companies. As for engineered bamboo, two participants put forward that it is suitable for residence as well as low-rise building, and retail building and leisure facility, respectively. From the perspective of companies, availability in the market is the biggest barrier to limit the use of engineered bamboo. Other factors include material cost, technology and fire performance are also the 
obstacle the development of these materials. And, more remarkable, several people mentioned lack of knowledge about material will limit its usage, both literature review and this questionnaire reflect this problem a lot.

The participants of the survey were asked to rank the materials: Cross-laminated timber (CLT), engineered bamboo, steel, concrete, masonry and timber-frame from the different aspects. According to overall tendency of the feedback, the marks of characteristics for engineered bamboo can be concluded generally in a way as shown in Table 2.

Engineered bamboo products were considered as the best performing in the aspects of aesthetics and environmental friendliness. It was found that engineered bamboo can be cost-efficient. In addition, its strength performance be can as good as concrete and steel, or even better with the special manufacturing.

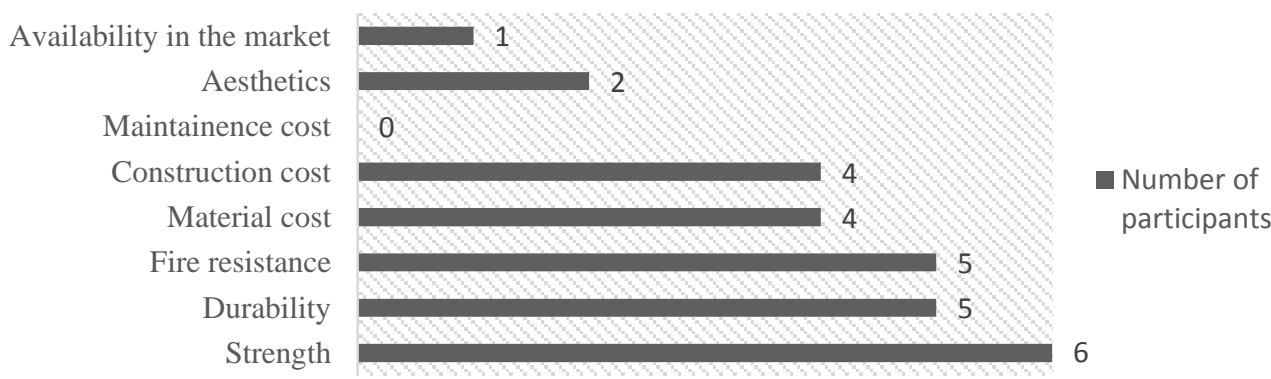

Figure 2. Participants' response on: 'The most important characteristics of material in construction'

Table 2. The characteristics marking of construction materials (Worst: 0 to Best: 5)

\begin{tabular}{cccc}
\hline CHARACTERISTIC & MARK & CHARACTERISTIC & MARK \\
Acoustic performance & 2.67 & Aesthetics & 4.44 \\
Availability in the market & 2.11 & Material cost (low to high) & 3.33 \\
Construction cost (low to high) & 2.89 & Maintenance cost (low to high) & 2.89 \\
Durability & 1.89 & Strength performance & 3.22 \\
Fire performance & 2.11 & Environmental friendliness & 3.67 \\
\hline
\end{tabular}

\section{Conclusions}

This study gives indication that engineering bamboo products have potential for utilization in construction industry in China as there are so many advantages of using bamboo. These are good strength to weight ratio, anti-seismicity, environmental friendliness, and economy when prefabricated. However, there are still many obstacles for engineered bamboo technology development, including: lack of relevant legislations, and design and construction codes. To improve the situation, it is suggested that more research effort from the main stakeholders, such as government and universities in China should be done to address different aspects of bamboo's further utilization in China. Moreover, the industry survey reviled that bamboo can have great potential in China due to the availability and properties. This paper presents preliminary results for bonding performance, the crucial property for engineered bamboo. The preliminary tests confirming this claim that when parameters are optimized, glued bamboo has the relatively high bonding shear strength, sufficient for construction. The relatively low clamping pressure of 0.6 MPa seems to be sufficient. However, it is recommended that further comprehensive studies on mechanical performance of engineered bamboo panels are carried out.

\section{Acknowledgments}

The authors would like to thank Xi'an Jiaotong-Liverpool University support for funding the Summer Undergraduate Research Fellowship (SURF) to undertake the project.

\section{References}

1. Kumar G and Ashish DK. Review on Feasibility of Bamboo in Modern Construction. SSRG International Journal of Civil Engineering. 2015: 4: 66-70.

2. Tan GY, Yang L. Tectonics of Bamboo. Nanjing: Southeast University Press, 2014.

3. Mera FAT, $\mathrm{Xu} \mathrm{CY}$. Plantation management and resource economics of bamboo in China. Ciencia y Tecnología. 2014: 7(1): 1-12.

4. Feng MZ, Zhao RL, Gao L, Zhang SB. Application and status of structure bamboo plywood. Wood Processing Machinery. 2012: 2: 45-51.

5. Yang XS. The current situation and future tendency of bamboo industry in China. Innovation and Industrialization. 2003: 2: 40-41.

6. Ju TW. Research and application of modern bamboo construction system [Master thesis]. Hunan University, 2013.

7. Xiao Y, Li J. The state of the art of modern bamboo structures. Industrial Construction. 2015: 45(4): 1-6. 
8. David F. The book of bamboo. Sierra Club Books, 1984.

9. Janssen JJA. Building with Bamboo: A handbook. 2rd ed. Practical Action Publishing, 1995.

10. Sun N, Zhang DB. Mechanical properties of bamboo. China Academic Journal Electronic Publishing House 1997: 19(3): 77-79.

11. Wang G, Jiang ZH, Liu XS, Fei BH, Zhang Y, Qiu YX. Status and future development of demoestic and foreign bamboo standards. China Wood Industry 2012: 26(4): 43-45.
12. Sikora K. S., McPolin D., Harte A. M., Shear strength and durability testing of adhesive bonds in crosslaminated timber, The Journal of Adhesion, Volume 92, Issue 7-9, 2016

13. Zhang S. Research on the Application of bamboobased composites material in the building [Master thesis]. Chongqing Jiaotong University, 2015.

14. Fei BH. The Analysis of Timber- framed Building Development in China. Paper presented at: International timber construction industry exchange conference, 2010, China. 